\title{
ГЕНДЕРНАЯ ИСТОРИЯ
}

Woman in Russian Society

2020. No. 2. P. 129-137

DOI: $10.21064 /$ WinRS.2020.2.11
Женщина в российском обществе

2020. № 2. C. 129-137

ББК 63.3(2)613-284.3

DOI: $10.21064 /$ WinRS.2020.2.11

\section{ПОЯИТИЧЕСКАЯ МОБИЯИЗАЦИЯ ЖЕНЩИН В 1920-Х ГГ. (На материалах Енисейской губернии)}

\author{
О. М. Долидович, Т. Г. Карчаева \\ Сибирский федеральный университет, г. Красноярск, Россия, \\ dolidovich@mail.ru
}

\begin{abstract}
Статья посвящена исследованию массовой политической мобилизации женщин в 1920-х гг. Проблема рассматривается на материалах Енисейской губернии. На основе анализа широкого комплекса архивных материалов и местной периодической печати показано, что для осуществления полномасштабной систематической работы среди женщин у партии и государства не было средств. Испытывая постоянный кадровый дефицит и нехватку финансирования, женотделы проводили работу по разъяснению крестьянкам и работницам их гражданских и политических прав, ликвидации неграмотности, развитию делегатского движения, повышению их электоральной активности и представительства в органах власти. Однако на протяжении всего изучаемого десятилетия женщины демонстрировали слабую мотивацию к участию в общественно-политической жизни, низкую способность к принятию управленческих решений, усвоению предлагавшейся им новой гендерной роли.
\end{abstract}

Ключевые слова: гендер, государственная политика в отношении женщин, Енисейская губерния, женотдел, политическая мобилизация.

\section{POLITICAL MOBILIZATION OF WOMEN IN THE 1920s (On materials of the Yenisei province)}

\section{O. M. Dolidovich, T. G. Karchaeva}

Siberian Federal University, Krasnoyarsk, Russian Federation, dolidovich@mail.ru

The article is devoted to the study of mass political mobilization of women in the 1920s. The problem is considered on the materials of the Yenisei province. The authors used a wide range of archival materials and local periodicals. They showed that the party and the state did not have the means to carry out full-scale, systematic work among women. The women's departments experienced a permanent shortage of personnel and lack of funding. But they explained to women their civil and political rights, developed the delegate movement, worked to eliminate illiteracy, increase the electoral activity of women and their representation in government. Female workers and peasant women demonstrated a weak motivation for participation in public and political life, a low ability to make managerial decisions, and the assimilation

(C) Долидович О. М., Карчаева Т. Г., 2020 
of a new gender role. Party leaders in the regions of the country for a long time did not understand the purposes and meaning of Soviet policy on women and virtually ignored it. The authors concluded that the situation could not be different in agrarian regions with undeveloped social infrastructure, insignificant industrial production, predominance of rural population with such features as low level of education and social mobility, collectivism, religiosity. For this reason, the next stage of the national gender policy in 1930-1950s was associated with the process of accelerated economic modernization of the country.

Key words: gender, state policy on women, Yenisei province, the Women's Department of the All-Russian Communist Party (Bolsheviks) (the Zhenotdel), political mobilization.

\section{Введение}

После свержения Временного правительства в октябре 1917 г. большевики приступили к строительству Советской республики. Согласно их концепции, в государственном управлении и выработке решений по всем вопросам развития страны должны были принимать участие широкие слои населения. Работницы и крестьянки рассматривались в качестве одной из наиболее многочисленных социальных групп, способных обеспечить политическую поддержку новой власти, и в то же время отсталых, в отношении которых требовалась серьезная просветительская и пропагандистская работа. В 1920-х гг. они стали объектом целенаправленного государственного воздействия.

Специфике советского варианта женской эмансипации посвящено значительное число работ (см., напр.: [Clements, 1992; Goldman, 1993; Здравомыслова, Темкина, 2003; Хасбулатова, 2005; Young, 2008; Алферова, 2011; Пушкарева, 2015]). В них выделены основные этапы государственной политики в отношении женщин, проанализирован вопрос о ее преемственности с российским феминистским движением дореволюционного периода, охарактеризованы гендерные различия и изменения в сфере занятости, семейно-брачных отношений.

Период с 1918 г. до конца 1920-х гг. исследователи определили как этап политической мобилизации женщин на решение политических и экономических проблем страны. Однако дискуссионным вопросом в историографии остаются причины расформирования женотделов в 1930 г. Согласно одной из точек зрения, большевики опасались, что работа с женщинами могла стать потенциальным основанием для возникновения оппозиции из-за роста их гражданского самосознания [Стайтс, 2004: 464-466; Юкина, 2007: 448-450]. По мнению других исследователей, женский вопрос ушел из списка приоритетных целей внутренней политики во второй половине 1920-х гг., поскольку женотделы выполнили свое основное назначение - воспитание крестьянок и работниц в духе социализма [Козлова, 2011].

Разработка вопроса о массовом выдвижении женщин в сферу общественнополитической деятельности на материалах российских регионов позволяет поновому взглянуть на проблему, так как показывает особенности и противоречия процесса реализации новой гендерной политики представителями власти на местах.

На материалах восточносибирской Енисейской губернии предлагаем рассмотреть кадровый состав женотделов, поскольку именно через эту партийную 
структуру осуществлялись массовая мобилизация работниц и крестьянок в публичное пространство, развитие делегатского движения в качестве ее основного инструмента, а также отслеживались результаты выдвижения женщин в партийные и представительные органы власти к концу изучаемого периода.

Анализ гендерных аспектов политической мобилизации проводился на основе структурно-конструктивистского подхода, согласно которому понятие «гендерный порядок» того или иного общества означает исторически сложившуюся систему отношений между полами, поддерживаемую совокупностью социальных механизмов и комплексом контекстов (политический, образовательный, профессиональный и др.). Гендер является частью политического процесса, поскольку воспроизводится и сам воспроизводит распределение власти. Гендерный порядок советского общества определяется как этакратический, т. е. заданный государством, осуществлявшим нормативное регулирование половых отношений, механизмы разделения труда между полами, модели мужественности и женственности.

Комплекс неопубликованных источников представлен делопроизводственной и отчетной документацией Енисейского губернского и Красноярского уездного комитетов РКП(б), исполкома Красноярского городского Совета народных депутатов, сосредоточенной в Государственном архиве Красноярского края (ГАКК). Анализ писем и циркуляров ЦК РКП(б), личных дел сотрудников партийных комитетов, советов, исполкомов, отчетов и протоколов женских собраний, конференций позволяет реконструировать процесс создания губернского и уездных женотделов в сложных условиях завершения Гражданской войны, нэпа и второй половины 1920-х гг., направления и особенности их работы, выявить отношение местных управленцев к работе среди женщин.

Среди опубликованных источников большое значение имеет периодическая печать. Журнал Сибирского революционного комитета (после его упразднения в 1925 г. - Сибирского краевого исполкома Совета депутатов) «Жизнь красной Сибири» (с 1922 г. - «Жизнь Сибири») и газета «Советская Сибирь» освещали важнейшие решения партийных и государственных органов, ход выборных кампаний в Советы. В журнале «Красная сибирячка», издававшемся отделом по работе среди женщин при Сибкрайкоме РКП(б), публиковались сведения о выборах делегаток и работе делегатских собраний, деятельности волорганизаторов в сибирской деревне и др. Газета «Красноярский рабочий» отражала особенности экономического развития и социально-демографических процессов в Енисейской губернии. В 1920-1922 гг. работе среди женщин была посвящена последняя страница газеты («Страница работницы»), которую вел губженотдел, в 1923 г. — рубрика «Наш женотдел».

В процессе работы с источниками принимались во внимание их ярко выраженный пропагандистский характер и ориентация на демонстрацию преимуществ социалистического строя. Кроме того, учитывалось, что в начале 1920-х гг. советские органы власти находились в стадии становления, переживали многочисленные реорганизации, испытывали недостаток кадров и финансирования - все это отражалось на качестве их документооборота. В значительной степени такая ситуация была характерна и для женотделов, делопроизводство которых велось небрежно. 


\section{Кадровый состав женотделов}

Формирование партийно-государственных структур в Енисейской губернии началось после того, как в 1920 г. отряды Красной армии освободили ее от колчаковских войск. В течение ноября 1920 г. — января 1921 г. были созданы женотделы: губернский (губженотдел) и по одному в каждом из 5 уездов Красноярском, Канском, Минусинском, Ачинском, Енисейском (уженотделы). В составе губженотдела числились заведующая, секретарь и 2 инструктора, уженотделов - заведующая и по 1 инструктору; всего 14 сотрудниц. Для работы с крестьянками в уездах местные коммунистические партийные ячейки должны были выбрать волостного организатора (волорганизатора, после начала районирования Сибири в 1923 г. - райженорганизатора) или его назначал уездный отдел работниц. К 1923 г. на 164 волости приходилось 46 волорганизаторов [ГАКК, ф. П-1, оп. 4, д. 816, л. 43 об.].

Для того чтобы наладить системную работу среди женщин в одной из самых обширных губерний в стране, такого количества сотрудников было явно недостаточно. Однако дефицит средств не позволял не только расширить штат, но и обеспечить выплату заработной платы служащим. Сотрудниц женотделов трудоустраивали на неполный рабочий день в разные партийные отделы на должности машинисток, делопроизводителей и т. п., т. е. жалованье они получали частями и в нескольких подразделениях. Волорганизаторы числились в составе волостных исполкомов и не были включены в штаты партийных комитетов, их зарплата должна была выплачиваться из «местных средств», т. е. за счет самообложения крестьян. Если волорганизатор приезжал на работу по направлению уженотдела, то последний и должен был самостоятельно изыскать деньги на оплату его труда [там же, оп. 1, д. 256, л. 1-3].

На протяжении изучаемого периода для сотрудниц женотделов Енисейской губернии был характерен крайне низкий уровень образования. Назначение и продвижение по карьерной лестнице определялись прежде всего классовыми и политическими критериями, а не квалификацией и профессионализмом. К тому же если на ведущие должности в губернские и уездные ревкомы и бюро РКП(б) направляли политработников, командированных от Центрального Комитета или Сибирского революционного комитета, то в рамках выдвиженческой и мобилизационной работы региональные партийные органы должны были исходить из местных условий. В Сибири ситуация была такова, что уровень женской грамотности и в дореволюционный период был значительно ниже, чем в губерниях европейской части страны. В 1920-х гг. не произошло значительных изменений. Согласно материалам Всесоюзной переписи населения 1926 г., в сибирских губерниях были грамотными 43,4 \% мужчин, 18,8 \% женщин. При этом в городах грамотные мужчины составляли $67,0 \%$, в сельской местности - 40,0\%, грамотные женщины - 51,0 и 14,0\% соответственно [Всесоюзная перепись..., 1928: 26-27].

Данные об образовании сотрудниц в документации женотделов отражены обрывочно. К примеру, в отчете о работе губженотдела за март 1923 г. указано, что среди 7 заведующих и 1 инструктора не было никого с высшим или полным средним образованием, 3 человека окончили начальную школу. Относительно 
еще 5 не приведено никаких сведений, лишь обозначено, что они состояли в партии. Образовательный уровень волорганизаторов чаще всего вовсе не фиксировался, поскольку подразумевалось, что это азбучная грамотность или начальная школа. Отмечались лишь их «способности к работе» или «политическая подготовка» [ГАКК, ф. П-1, оп. 4, д. 600, л. 48-49].

Дефицит кадров и их низкий образовательный уровень негативно сказывались на результатах работы. В первой половине 1920-х гг. отдел работниц Сибирского бюро ЦК РКП(б) оценивал деятельность Енисейского губженотдела в уездах как очень слабую, заведующие уженотделов не выезжали в волости, в отчетах ничего не говорилось о мероприятиях по ликвидации неграмотности крестьянок, их вовлечении в комитеты общественной взаимопомощи, введении в состав сельских Советов [там же, оп. 1, д. 407, л. 174].

Переход к нэпу лишь усугубил ситуацию, потому что в стране началось масштабное сокращение административно-управленческого аппарата. В Енисейской губернии в уездных женотделах осталось только по одной заведующей, в губженотделах — по заведующей и инструктору. Финансирование женотделов было практически прекращено.

Вопрос о результатах работы партии среди работниц и крестьянок обсуждался на XI, XII и XIII съездах РКП(б), проходивших в Москве в 1922-1924 гг. Местные комитеты партии получили распоряжение оказать содействие женотделам, обратить внимание на более полное комплектование их состава и подготовку, установить связь с организационно-инструкторскими и агитационнопропагандистскими отделами партийных комитетов, выделить средства на командировочные расходы.

Тем не менее значительного увеличения финансирования женотделов или кардинальных изменений кадрового состава вплоть до конца 1920-х гг. не произошло. Организовать системную эффективную работу среди женщин в условиях аграрной Енисейской губернии, где поселения находились на больших расстояниях друг от друга, многие крестьяне проживали на хуторах и заимках, при неразвитой транспортной инфраструктуре не представлялось возможным [За улучшение работы..., 1925: 2].

\section{Делегатское движение}

Вовлечение женщин в процесс партийно-государственного строительства, а также их политическое, идеологическое воспитание осуществлялось через делегатское движение, которое должно было стать «кузницей женских кадров», готовить из них «будущих управленцев» [Алферова, 2011: 47].

Согласно отчетам Енисейского губженотдела, в течение 1921-1922 гг. выборы делегаток проходили только в Красноярске. За этот период было избрано порядка 50 делегаток из числа домохозяек, вдов и жен красноармейцев. В своем звании они числились формально, собрания не посещали, на работу в советские учреждения их не направляли [ГАКК, ф. П-1, оп. 1, д. 407, л. 174].

Местные женотделы испытывали большие затруднения с тем, чтобы обеспечить показатели численности делегаток-работниц, поскольку здесь не существовало крупных промышленных предприятий. Так, в ходе выборов в Красноярском уезде 
в сентябре - ноябре 1923 г. губженотдел провел в состав делегаток около $50 \%$ учительниц. Но уже в феврале 1924 г. было получено предписание Сиббюро ЦК РКП(б) о проведении частичных перевыборов: «Среди интеллигенток мы, как правило, работы не должны вести. Среди них должна вести работу партия в целом и профсоюзы. Наша задача — подтянуть к общему уровню и влить в общие ряды отсталую работницу и крестьянку» [там же, оп. 4, д. 816, л. 47 об.]. Осенью 1924 г. состоялось 62 делегатских собрания, было избрано 1138 делегаток. В процентном соотношении преобладали крестьянки - 64,0 \% (725 чел.). Работницы составляли лишь 8,0 \% (90 чел.) делегаток. Еще 12,0 \% (138 чел.) было избрано из числа батрачек, 9,0 \% (103 чел.) - из числа служащих (учительницы и машинистки) и 7,0 \% (82 чел.) — из числа домохозяек [там же, д. 960, л. 38].

Мотивация горожанок к работе в качестве делегаток была низкой. Во-первых, многие советские учреждения встречали их с непониманием: «Отделы Советов не представляли себе определенно, что собственно должна делать у них делегатка, а иногда и просто считали работу с ними лишним бременем для себя» [Работа делегаток..., 1921: 4]. Во-вторых, малооплачиваемый, а часто неоплачиваемый труд делегатки не привлекал женщин. Женотделы отмечали, что делегатки работают небрежно. К примеру, когда в 1929 г. делегаткам и комсомольцам, прикрепленным к пунктам ликвидации неграмотности Красноярска, было поручено собрать информацию об образовании жителей некоторых районов города, они прибегли к подаче фальсифицированных данных [Комсомол и делегатки..., , 1929: 3].

В уездах работа с делегатками в начале 1920 -х гг. практически не велась из-за крупных антисоветских восстаний. В октябре 1920 г. в Канском уезде вспыхнул так называемый «голопуповский» мятеж, в феврале 1921 г. на территории Ачинского и Минусинского уездов - восстание под предводительством казака И. Н. Соловьева. Крестьянки многих деревень встречали сотрудниц женотделов враждебно. На собраниях женщин в селах звучали «контрреволюционные выступления»: «Не надо нам делегаток, они будут защищать советскую власть» [ГАКК, ф. П-1. оп. 4, д. 819, л. 100 об.].

К середине 1920-х гг. в тех уездах, которые находились ближе к губернскому центру, выборы делегаток проходили относительно регулярно. Однако на селе их высмеивали и оскорбляли, мужья не разрешали женщинам посещать встречи и конференции, сами женщины избегали общественной работы. В случае обращения делегатки в сельский Совет с каким-либо вопросом или жалобой чаще всего не следовало никакой реакции: «Деревенские, советские, кооперативные и другие органы еще недостаточно уяснили себе значение делегатских собраний и частенько не только не помогают им в работе, а, наоборот, тормозят» [Меламед, 1925: 5].

Согласно оценкам Сиббюро ЦК РКП(б), работа среди делегаток в уездах Енисейской губернии к 1928 г. была поставлена неудовлетворительно. Большинство из них по-прежнему не умели читать и писать. Крестьянки не понимали смысла делегатского движения, зачастую на собраниях разбирались семейные ссоры и склоки, что вызывало ироничное отношение населения и дискредитировало саму идею делегатского движения. Во многих случаях делегатки не избирались, а назначались решением сельсовета или райженорганизатора. В этом статусе они числились формально, к практической деятельности не приступали. 


\section{Женщины в партийных и представительных органах власти}

Численность женщин в партийных комитетах Енисейской губернии на протяжении всего изучаемого периода росла медленно. В 1923 г. среди членов и кандидатов РКП(б) в Красноярске женщины составляли 11,7\% (129 из 1101 чел.), в уездах - 4,4 \% (176 из 3393 чел.), всего по губернии - 16,1\%. К концу 1920-х гг. соотношение мужчин и женщин среди кандидатов и членов партии изменилось незначительно [ГАКК, ф. П-1, оп. 3, д. 8а, л. 1-37].

При выдвижении женщин в состав представительных органов государственной власти (Советы) женотделы губернии также столкнулись с серьезными трудностями. Местные управленцы не относили работу среди женщин к числу приоритетных партийных задач, не понимали ее целей, не считали себя ответственными за нее. Так, в 1924 г. на выборах сотрудников сельсоветов Ужурской волости Ачинского уезда инструктор женотдела настаивала на введении в их состав женщин. Коммунисты отреагировали издевательской шуткой — избирали только крестьянок. Сразу же началась процедура перевыборов, поскольку всем было очевидно, что в качестве председателей и депутатов они работать не смогут [там же, оп. 4 , д. 819 , л. 100 об.].

Показатели по вовлечению женщин в перевыборные кампании Советов были максимально высокими в губернском центре - Красноярске. Так, в 1926 г. среди депутатов и кандидатов в депутаты Красноярского городского совета женщин было 28,0\% (65 из 232 чел.), в 1928-1929 гг. - 24,7\% (66 из 267 чел.). Среди депутатов и кандидатов в депутаты Советов уездных городов губернии численность женщин на протяжении 1920-х гг. не превышала 20,0 \% [там же]. В 1928-1929 гг. среди депутатов и кандидатов в депутаты сельских Советов Красноярского округа женщины составляли 13,6 \% (29 из 213 чел.), по другим округам в целом - также не более $13 \%$ [там же, ф. Р-631, оп. 1, д. 67, л. 1-2].

Доля женщин в составе исполкомов советов Енисейской губернии тоже увеличивалась медленно. Заведующие женотделами отмечали, что в сельских Советах неграмотные и многодетные крестьянки чаще всего просто числились, на заседания не приходили, да их и не приглашали.

В процессах принятия решений секций горсоветов (коммунального хозяйства, финансово-бюджетной, народного образования, здравоохранения, кооперативно-торговой и др.) женщины, как правило, также участия не принимали. Во всех исполкомах Сибири существовал повышенный спрос на специалистов с профильным образованием, но, поскольку женщины не соответствовали этому требованию, они преимущественно занимали должности секретарей, машинисток [Из сводки..., 1921: 12-13]. Так, в 1920-1921 гг. в составе президиума Енисейского губкома женщины составляли 18,0 \% (2 из 11 чел.), а среди сотрудников, ведущих делопроизводство управления делами губкома, - 70,0 \% (7 из 10 чел.) [ГАКК, ф. П-1, оп. 1, д. 256, л. 1-3]. В 1928-1929 гг. среди сотрудников Енисейского губкома доля женщин достигала 10 \% (45 из 445 чел.) [там же, оп. 3 , д. 8а, л. 1-37]. 


\section{Заключение}

Целью советской политической мобилизации женщин в 1920-х гг. была активизация их гражданского участия для того, чтобы обеспечить поддержку режима и его устойчивость. Однако курс на массовое вовлечение работниц и крестьянок в сферу общественно-политической деятельности в условиях дефицита ресурсов, которыми располагало новое государство (финансовые, организационные, социальные, культурные), не давал быстрых результатов. Расформирование женотделов в 1930 г. можно рассматривать как смену стратегии большевиков, которые пришли к пониманию того, что в условиях аграрной страны (с такими характеристиками, как незначительное развитие промышленного производства, преобладание сельского населения, низкий уровень образования и социальной мобильности) принудительная активизация женского гражданского участия не могла быть осуществлена только через женотделы. Требовалось широкое вовлечение женщин в производство, что означало необходимость масштабной модернизации всех сфер жизни общества.

\section{Библиографический список}

Алферова И. В. Делегатские собрания 1920-х годов как проект подготовки советских женщин к управленческой деятельности // Magistra vitae: электронный журнал по историческим наукам и археологии. 2011. № 1. С. 46-54.

Всесоюзная перепись населения, 17 декабря 1926 г.: краткие сводки. М.: ЦСУ Союза ССР, 1928. Вып. 7: Возраст и грамотность населения СССР.

ГАКК (Государственный архив Красноярского края).

За улучшение работы сельсоветов // Красноярский рабочий. 1925. № 184. С. 2.

Здравомысслова $E$. А., Темкина А. А. Государственное конструирование гендера в советском обществе // Журнал исследований социальной политики. 2003. Т. 1, № 3 - 4 . C. $299-320$.

Из сводки информационно-инструкторского подотдела // Жизнь красной Сибири. 1921. № 3 - 4. C. $12-13$.

Козлова Н. Н. Гендерная модернизация советской политической системы: институциональный аспект // Женщина в российском обществе. 2011. № 4. C. $38-42$.

Комсомол и делегатки плохо провели перепись неграмотных // Красноярский рабочий. 1929. № 14. C. 3.

Меламед. Надо готовиться к перевыборам делегатских собраний // Красная сибирячка. 1925. № 8. C. 5.

Пушкарева Н. Л. Гендерная система советской России и повседневность россиянок // Повседневная жизнь при социализме. Немецкие и российские подходы / под ред. Я. К. Берендса, В. С. Дубиной, А. К. Сорокина. М.: РОССПЭН, 2015. С. $204-226$.

Работа делегаток в советских отделах // Советская Сибирь. 1921. № 103. С. 4.

Стайтс P. Женское освободительное движение в России: феминизм, нигилизм и большевизм, 1860-1930. М.: РОССПЭН, 2004. $616 \mathrm{c.}$

Хасбулатова О.А. Российская гендерная политика в ХХ столетии: мифы и реалии. Иваново: Иван. гос. ун-т, 2005. 372 с.

Юкина И. И. Русский феминизм как вызов современности. СПб.: Алетейя, 2007. 544 с.

Clements B. E. The utopianism of the zhenotdel // Slavic Review. 1992. Vol. 51, iss. 3. P. $485-496$. 
Goldman W. Z. Women, the State and Revolution: Soviet Family Policy and Social Life, 1917-1936. Cambridge: Cambridge University Press, 1993. 351 p.

Young J. P. Bolshevik Wives: a Study of Soviet Elite Society. Sydney: Sydney University, 2008. $243 \mathrm{p}$.

\section{References}

Alferova, I. V. (2011) Delegatskie sobraniia 1920-kh godov kak proekt podgotovki sovetskikh zhenshchin k upravlencheskor deiatel'nosti [Delegates' meetings of the 1920s as a project to prepare Soviet women for management], Magistra Vitae: èlektronnyı̆ zhurnal po istoricheskim naukam i arkheologii, no. 1, pp. 46-54.

Clements, B. E. (1992) The utopianism of the zhenotdel, Slavic Review, vol. 51, iss. 3, pp. $485-496$.

Goldman, W. Z. (1993) Women, the State and Revolution: Soviet Family Policy and Social Life, 1917-1936, Cambridge: Cambridge University Press.

Iukina, I. I. (2007) Russkii feminizm kak vyzov sovremennosti [Russian feminism as a challenge to modernity], St. Petersburg: Aleteriia.

Khasbulatova, O. A. (2005) Rossiüskaia gendernaia politika $v$ XX stoletii: mify i realii [Russian gender policy in the XX century: myths and realities], Ivanovo: Ivanovskii gosudarstvennyı̆ universitet.

Kozlova, N. N. (2011) Gendernaia modernizatsiia sovetskor politicheskoř sistemy: institutsional'nyı aspekt [Gender modernization of the Soviet political system: an institutional aspect], Zhenshchina v rossiüskom obshchestve, no. 4, pp. 38-42.

Pushkareva, N. L. (2015) Gendernaia sistema sovetskoĭ Rossii i povsednevnost' rossiianok [Gender system of Soviet Russia and everyday life of Russian women], in: Berends, Ia. K., Dubina, V. S., Sorokin, A. K. (eds), Povsednevnaia zhizn' pri sotsializme. Nemetskie i rossiüskie podkhody, Moscow: ROSSPĖN, pp. 204-226.

Staits, R. (2004) Zhenskoe osvoboditel'noe dvizhenie $v$ Rossii: feminizm, nigilizm $i$ bol'shevizm, 1860-1930 [Women's liberation movement in Russia: feminism, nihilism and bolshevism, 1860-1930], Moscow: ROSSPE்N.

Young, J. P. (2008) Bolshevik Wives: A Study of Soviet Elite Society, Sydney: Sydney University.

Zdravomyslova, E. A., Temkina, A. A. (2003) Gosudarstvennoe konstruirovanie gendera v sovetskom obshchestve [State construction of gender in Soviet society], Zhurnal issledovaniı̌ sotsial'noĭ politiki, vol. 1, no. 3-4, pp. 299-320.

Статья поступила 15.07.2019 2.

\section{Информация об авторах / Information about the authors}

Долидович Олеся Михайловна - кандидат исторических наук, доцент кафедры современных образовательных технологий, Сибирский федеральный университет, г. Красноярск, Россия, dolidovich@mail.ru (Cand. Sc. (History), Associate Professor at the Department of Modern Educational Technologies, Siberian Federal University, Krasnoyarsk, Russian Federation).

Карчаева Татьяна Геннадьевна - кандидат исторических наук, доцент кафедры истории России, Сибирский федеральный университет, г. Красноярск, Россия, tatyana-verhoturova@yandex.ru (Cand. Sc. (History), Associate Professor at the Department of History of Russia, Siberian Federal University, Krasnoyarsk, Russian Federation). 